ఠ ORIGINAL RESEARCH

\title{
Intraocular pressure-lowering effect of oral paracetamol and its in vitro corneal penetration properties
}

This article was published in the following Dove Press journal:

Clinical Ophthalmology

25 January 2013

Number of times this article has been viewed

\author{
Nabiel Mohamed \\ David Meyer \\ Division of Ophthalmology, Faculty \\ of Medicine and Health Sciences, \\ University of Stellenbosch, Cape \\ Town, South Africa
}

Background: Several studies have confirmed the ability of cannabinoids to reduce intraocular pressure. Experimental data recently demonstrated unequivocally that the analgesic effect of paracetamol is due to its indirect action on cannabinoid receptors. The question then arises as to whether paracetamol can reduce intraocular pressure via its effect on intraocular cannabinoid receptors.

Methods: A 2-week, prospective, randomized, controlled, single-center, parallel-group pilot study was carried out to determine the efficacy and safety of paracetamol $1 \mathrm{~g}$ orally administered every 6 hours in adult patients with primary or secondary open angle glaucoma as compared with topical levobunolol $0.5 \%$ twice a day. Patient well-being was closely monitored throughout the study and focused on hepatic safety in accordance with Drug-Induced Liver Injury Network criteria. The in vitro diffusion kinetics of acetaminophen in a phosphate-buffered solution in rabbit and human corneas was also investigated, with the view to a topical application.

Results: Eighteen adult patients were enrolled in the study, with nine in the topical levobunolol group and nine in the oral paracetamol group. In the levobunolol group, the mean reduction in intraocular pressure at day 7 was $7.5 \mathrm{mmHg}(P<0.008)$ and at day 14 was $9.1 \mathrm{mmHg}$ $(P<0.005)$, from a mean baseline intraocular pressure of $29.6 \mathrm{mmHg}$. The corresponding figures for the paracetamol group were $8.8 \mathrm{mmHg}(P<0.0004)$ at day 7 and $6.5 \mathrm{mmHg}(P<0.004)$ at day 14 , from a mean baseline intraocular pressure of $29.4 \mathrm{mmHg}$. Both study regimens were well tolerated. No serious treatment-related adverse events were reported in either of the treatment groups. Liver function tests, systolic/diastolic blood pressure, or heart rate remained unchanged in both groups during the 2 weeks of the study. In the laboratory study, paracetamol $1 \mathrm{mg} / \mathrm{mL}$ in phosphate-buffered solution ( $\mathrm{pH}$ 7.4) showed acceptable flux rates. Steady-state levels were achieved within 12 hours, thus confirming that paracetamol penetrates the cornea well.

Conclusion: Paracetamol $1 \mathrm{~g}$ taken orally every 6 hours reduced open angle glaucoma and/or angle recession glaucoma in both groups of patients, in a way comparable with that achieved by a topical beta-adrenergic receptor antagonist.

Keywords: acetaminophen, paracetamol, glaucoma, intraocular pressure, cannabinoids

\section{Introduction}

Medical therapy for raised intraocular pressure and glaucoma has expanded significantly in the past few years. Five major classes of ocular hypotensives are currently available for topical and systemic use. These include the beta-adrenergic receptor antagonists ( $\beta$-blockers), alpha-adrenergic receptor agonists ( $\alpha$-agonists), carbonic anhydrase inhibitors, parasympathomimetic agents (miotics), and the newest category, the ocular hypotensive lipids (also known as prostaglandin analogs). These agents are used either alone or as combination therapy. ${ }^{1}$
Correspondence: Nabiel Mohamed Division of Ophthalmology, Faculty of Medicine and Health Sciences, University of Stellenbosch, Francie van Zijl Avenue, Parow 7505, Cape Town, South Africa Tel +27219389380

Fax +272 193। 8437

Email nabiel.mohamed@gmail.com 
Numerous studies have shown that different systemic or topical cannabinoids can reduce intraocular pressure. ${ }^{2}$ The cannabinoid receptor is expressed in the central nervous system, including in the human eye, as well as in numerous other tissues, and it has been recognized as an important therapeutic target for glaucoma. ${ }^{3}$

Although paracetamol (acetaminophen) has been used clinically for more than a century, ${ }^{4}$ its mechanism of action has not been clearly understood. Recent experimental data have demonstrated unequivocally that the analgesic effect of paracetamol is due to indirect activation of cannabinoid receptors. ${ }^{5-7}$ In the brain and spinal cord, paracetamol, following deacetylation to its primary amine (p-aminophenol), is conjugated with arachidonic acid to form $\mathrm{N}$-arachidonoylphenolamine (AM404), an endogenous cannabinoid. ${ }^{7}$ Therefore, paracetamol acts as a prodrug for the active cannabinoid, AM404, which appears to stimulate cannabinoid receptors, and does not act solely as a cyclo-oxygenase- 3 inhibitor as previously thought. These findings offer an explanation for the mechanism of action of the procannabinomimetic drug, paracetamol, and its effects, including behavioral aspects.

The recent identification of cannabinoid receptors and their endogenous lipid ligands has triggered much research on the endocannabinoid system and its regulatory functions in health and disease. ${ }^{8}$ Recent studies suggest that cannabinoid-like drugs relax the bovine ophthalmic artery via the cannabinoid receptor-sensitive pathway. ${ }^{9}$ Naturally occurring cannabinoids have the potential to become useful treatment modalities for glaucoma, because they appear to have neuroprotective properties and effectively reduce intraocular pressure, possibly via the cannabinoid receptor. ${ }^{10}$ However, there are potential challenges with their chronic systemic use, including systemic side effects, possible tolerance, and the difficulty in formulating stable and effective topical preparations. To minimize possible systemic adverse effects and maximize efficacy at the site of action, topical ocular application of cannabinoid agonists would be ideal. However, natural cannabinoid extracts as well as synthetic forms are highly lipophilic, creating formulation problems with aqueous preparations associated with this mode of administration. $^{2}$

Paracetamol is a well established and safe drug when taken at an appropriate dosage, is uniformly distributed throughout most body fluids, freely crosses the blood-brain barrier, and its drug interactions and toxic potential are well recognized. Ophthalmology is continually seeking new drugs and novel mechanisms of action for the treatment of glaucoma. The discovery of the mechanism of action of paracetamol now provides a sound scientific basis for clinicians and researchers to assess its effect as a procannabinomimetic drug for the treatment of intraocular pressure.

We have explored these concepts in a pilot clinical study comparing the intraocular pressure-lowering effect of oral paracetamol with that of levobunolol over a 2-week period, and investigating the in vitro diffusion kinetics of paracetamol in phosphate-buffered solution in rabbit and human corneas in the laboratory.

\section{Materials and methods}

A 2-week, prospective, randomized, controlled, single-center, parallel-group pilot study was carried out to compare the efficacy and safety of orally administered paracetamol with that a topical $\beta$-blocker (levobunolol $0.5 \%$ ) in otherwise healthy adult patients with primary or secondary glaucoma or ocular hypertension. Ethical approval from the human ethics committee of the University of Stellenbosch, South Africa, was obtained separately for the clinical and in vitro studies. All participants signed an informed consent form before enrolment. The study was performed in accordance with the tenets of the Declaration of Helsinki and was conducted according to a protocol and standard operating procedures meeting the guidelines laid down by the International Conference on Harmonisation for Good Clinical Practice in clinical trials.

Participants enrolled in the clinical study were $\geq 21$ years of age, of any race and gender, and diagnosed with ocular hypertension, angle recession glaucoma, or open angle glaucoma. Only treatment-naïve patients and those who had not received any intraocular pressure-lowering therapy for 4 weeks prior to commencement of the study were included. A baseline intraocular pressure $\geq 21 \mathrm{mmHg}$ in at least one eye was required. Exclusion criteria were clinically significant hematologic or hepatic abnormalities, a positive human immunodeficiency virus screening test, and contraindications to the use of paracetamol or $\beta$-blockers.

Study visit schedules included a baseline visit, a screening visit (within one week of the baseline visit) and at weeks 1 and 2 after commencing therapy. At all visits, a full physical examination (including hematological and urine analyses), best-corrected visual acuity, and slit-lamp biomicroscopy of the anterior segments were performed, along with intraocular pressure measurements (every attempt was made to measure intraocular pressure at $9 \mathrm{am}$ ). Gonioscopy was performed and central corneal thickness measured at the screening visit only. Dilated optic disc examinations and visual field assessments (Humphrey Field Analyzer 24:2 program) were included at the screening visit and at the end of the study period. 
Patients were assigned according to a predefined randomization schedule to one of two treatment groups: one group receiving topical levobunolol $(0.5 \%)$ eye drops, one drop 12 hourly (standard of care), while the other group received oral paracetamol $1 \mathrm{~g} 6$ hourly. Patients using paracetamol were provided with a logbook and instructed to note carefully the time when the tablets were taken. They were also asked to avoid consuming excessive amounts of alcohol.

\section{Outcomes}

The eye with the higher mean intraocular pressure at baseline was selected for the purpose of the study. All applanation tonometer readings were performed by the same examiner (NM). Intraocular pressure was measured at least twice in each eye, and if the difference between the first and second reading was $>2 \mathrm{mmHg}$, a third reading was taken. The mean of the readings was used for analysis.

Primary outcomes were absolute differences in intraocular pressure at the end of the 2-week treatment period compared with baseline within in both treatment groups and the efficacy of intraocular pressure reduction at the end of the 2-week treatment period compared with baseline between the treatment groups.

Secondary outcomes included absolute differences in intraocular pressure at 7 days compared with baseline between the treatment groups, and safety of the study medication used, assessed in terms of: mean changes in alanine transaminase (ALT), aspartate transaminase (AST), serum total bilirubin (TB), and alkaline phosphatase (ALP) levels at the end of the treatment period; number of subjects who developed hepatotoxicity; number of subjects who met Drug-Induced Liver Injury (DILI) Network criteria ${ }^{11,12}$ for drug-induced hepatic injury; and number of subjects who developed changes in hematological, urinary, blood pressure, or heart rate values from baseline.

\section{Permeability experiments}

The in vitro corneal permeability studies were performed in our own laboratories and according to our standard published methodology. ${ }^{13-16}$ Harvested human donor corneas were obtained from The Eye Bank Foundation of South Africa, Observatory, Cape Town, South Africa. Human corneas which were deemed unsuitable for transplantation because of, eg, hepatitis B and human immunodeficiency virus infections, were used for the study. Excised corneas were obtained from freshly slaughtered rabbits (Country Lane Nursery Farm, Kraaifontein, Cape Town, South Africa). All corneas collected were immediately placed in MK solution and transported to our laboratory within 6 hours. The MK solution consisted of a stock solution of Medium 199 (Sigma Chemical Company, St Louis, MO) without sodium bicarbonate, to which the latter as well as $25 \mathrm{mM}$ HEPES and $5 \%$ dextran were added prior to transport of the corneal specimens. The corneas were snap-frozen in liquid nitrogen and stored at $-85^{\circ} \mathrm{C}$ until use.

No specimens were obtained in which there was clinical evidence of corneal disease that might have influenced the permeability characteristics of the cornea. Tissue specimens were thawed at room temperature in phosphate-buffered solution ( $\mathrm{pH}$ 7.4) prior to each permeability experiment. Although some damage may occur at the cellular level due to the freezing process, freezing as well as storage and thawing have been previously demonstrated to have no adverse effects on the permeability characteristics of the corneal tissue. The corneas were carefully cut so as not to damage either the endothelial or epithelial surfaces into $4 \mathrm{~mm}^{2} \mathrm{sec}-$ tions and mounted in flow-through diffusion cells (exposed areas $0.039 \mathrm{~cm}^{2}$ ) as previously described. Each experiment using the permeant molecule (paracetamol $1 \mathrm{mg} / \mathrm{mL}$ ) was repeated six times for the human and rabbit corneas, respectively. Corneal disks were equilibrated for 10 minutes with phosphate-buffered solution ( $\mathrm{pH} 7.4$ ) at $20^{\circ} \mathrm{C}$ in the flowthrough diffusion cells prior to the start of the experiment. The phosphate-buffered solution was then removed from the donor compartment and replaced with the permeant molecule. Phosphate-buffered solution at $20^{\circ} \mathrm{C}$ was pumped through the receiving chambers at a rate of $1.5 \mathrm{~mL} /$ hour and collected by a fraction collector at 2 -hour intervals for 24 hours. The permeability studies were performed under sink conditions, ie, at the completion of each run, the concentration of permeant molecule in the acceptor chamber never reached $10 \%$ of that in the donor compartment. The collected fractions were then analyzed for their permeant content by high performance liquid chromatography.

\section{Calculation of flux values}

Flux $(J)$ values across the membranes were calculated as:

$$
J=Q / A \times t\left(\mu \mathrm{g} \times \mathrm{cm}^{-2} \times \mathrm{min}^{-1}\right)
$$

where $Q$ is the quantity of substance crossing membrane (in micrograms), $A$ is the membrane area exposed (in square centimeters), and $t$ is the time of exposure (in minutes).

\section{Steady-state kinetics}

When no statistically significant $(P<0.05)$ differences (using analysis of variance and Duncan multiple range test) 
between flux values were obtained over at least two consecutive time intervals, steady-state equilibrium kinetics were assumed to have been reached for a particular corneal specimen and paracetamol.

\section{Statistical analysis}

The primary analysis of the clinical study arm was a singlesample $t$-test. Based on a power analysis, this design would achieve $80 \%$ power to detect a reduction in intraocular pressure $\geq 5 \mathrm{mmHg}$ between baseline and week 2 . The difference from baseline to week 1 and week 2 was calculated and compared using the Student's $t$-test. Differences over time were also analyzed using a repeated-measures analysis of variance model, with the intraocular pressure at baseline, week 1, and week 2 as the response variables and group assignment as the fixed factor.

\section{Results \\ Efficacy}

Patients in the clinical arm of the study ranged in age from 28 to 81 (mean 55) years. The two treatment groups did not differ significantly with respect to age, race, gender, visual acuity, anterior segment signs, funduscopy, visual field tests, or body mass index.

Of the participants enrolled, 17 completed the study. One patient was excluded because of protocol deviations, including an inadequate time interval from dosing to intraocular pressure measurement and inappropriate dosing of the study medication. However, this patient's demographic characteristics, and baseline and 2-week blood results were used in the statistical analysis.

Individual intraocular pressure responses to the study medications and mean intraocular pressures for the two treatment groups are shown in Table 1. In the levobunolol $0.5 \%$ group, the mean intraocular pressure reduction at day 7 was $7.5 \mathrm{mmHg}(P<0.008)$ and at day 14 was $9.1 \mathrm{mmHg}$ $(P<0.005)$, from a mean intraocular pressure baseline of $29.6 \mathrm{mmHg}$. The corresponding numbers for the paracetamol group were $8.8 \mathrm{mmHg}(P<0.0004)$ at day 7 and $6.5 \mathrm{mmHg}$ $(P<0.004)$ at day 14 , from a mean intraocular pressure baseline of $29.4 \mathrm{mmHg}$. A mean reduction of $25 \%$ from baseline $(P=0.008)$ in six subjects $(67 \%)$ at week 1 and $29 \%$ from baseline $(P=0.005)$ in seven subjects $(78 \%)$ was obtained after 2 weeks of treatment with levobunolol. In the paracetamol group, a mean reduction of $29 \%$ from baseline $(P=0.0004)$ in seven subjects $(88 \%)$ and a reduction of $21 \%$ from baseline $(P=0.004)$ in five subjects $(63 \%)$ was obtained after one and 2 weeks, respectively.
Table I Individual patient intraocular pressure responses to topical levobunolol and oral paracetamol

\begin{tabular}{|c|c|c|c|c|}
\hline Patient & Diagnosis & $\begin{array}{l}\text { Baseline IOP } \\
(\mathrm{mmHg})\end{array}$ & $\begin{array}{l}\text { Week I } \\
(\mathrm{mmHg})\end{array}$ & $\begin{array}{l}\text { Week } 2 \\
(\mathrm{mmHg})\end{array}$ \\
\hline \multicolumn{5}{|c|}{ Levobunolol } \\
\hline I & $\begin{array}{l}\text { Angle } \\
\text { recession }\end{array}$ & 33 & 20 & 23 \\
\hline 2 & POAG & 24.5 & 14 & 14 \\
\hline 3 & POAG & 30 & 20 & 19 \\
\hline 4 & $\begin{array}{l}\text { Angle } \\
\text { recession }\end{array}$ & 29.5 & 35 & 21 \\
\hline 5 & $\begin{array}{l}\text { Angle } \\
\text { recession }\end{array}$ & 25 & 19 & 19 \\
\hline 6 & POAG & 27.5 & 18 & 18 \\
\hline 7 & POAG & 25.5 & 23 & 29 \\
\hline 8 & POAG & 40 & 24 & 16 \\
\hline \multirow[t]{2}{*}{9} & POAG & 31.5 & 26 & 26 \\
\hline & & Mean $29.6 \pm 4.9$ & $22.1 \pm 6.0$ & $20.6 \pm 4.8$ \\
\hline \multicolumn{5}{|c|}{ Paracetamol } \\
\hline I & $\begin{array}{l}\text { Angle } \\
\text { recession }\end{array}$ & 28 & 20 & 24 \\
\hline 2 & POAG & 41.5 & 31 & 31 \\
\hline 3 & POAG & 38.5 & 22 & 25 \\
\hline 4 & POAG & 23 & 16 & 19 \\
\hline 5 & POAG & 27.5 & 19 & 28 \\
\hline 6 & POAG & 27 & 17 & 21 \\
\hline 7 & $\begin{array}{l}\text { Angle } \\
\text { recession }\end{array}$ & 25 & 19 & 19 \\
\hline 8 & POAG & 24.5 & 21 & 16 \\
\hline 9 & POAG & 30 & - & - \\
\hline & & Mean $29.4 \pm 6.8$ & $20.6 \pm 4.6$ & $22.9 \pm 5.1$ \\
\hline
\end{tabular}

Abbreviations: IOP, intraocular pressure; POAG, primary open angle glaucoma.

\section{Safety}

No statistically significant changes in systolic/diastolic blood pressure, heart rate, or urinary parameters were observed over the 2-week period of the study in either treatment group.

ALT, AST, TB, and ALP remained unchanged during the study in both groups (Table 2). Hepatotoxicity was defined as serum ALT or AST > $1000 \mathrm{IU} / \mathrm{L}$, and drug-induced liver injury was based on the DILI Network criteria. ${ }^{17}$ These criteria define drug-induced liver injury as an elevation of serum ALT or ALP to three times the upper limit of the reference range and an increase in total serum bilirubin to 1.5 times the upper limit of the reference range. Both study regimens were well tolerated and no serious treatment-related adverse events were reported.

\section{Penetration studies}

Figures 1 and 2 show the corneal penetration and steadystate transcorneal levels achieved with paracetamol $1 \mathrm{mg} / \mathrm{mL}$ in phosphate-buffered solution ( $\mathrm{pH} 7.4$ ) in human and rabbit corneas, respectively, in several experiments. 
Table 2 Changes in liver function tests from baseline to week 2 for the levobunolol and paracetamol groups

\begin{tabular}{|c|c|c|c|c|c|}
\hline Variable & Mean change & SD & SE & $t$ value & $P$ value \\
\hline \multicolumn{6}{|c|}{ Levobunolol } \\
\hline TB & 0.67 & 2.2 & 0.7 & 0.9 & 0.40 \\
\hline ALT & -7.0 & 15.3 & 5.1 & -1.4 & 0.21 \\
\hline AST & -9.2 & 11.2 & 3.7 & -2.5 & 0.038 \\
\hline ALP & -14.8 & 41.9 & 14.0 & -1.1 & 0.32 \\
\hline \multicolumn{6}{|c|}{ Paracetamol } \\
\hline TB & -1.22 & 2.1 & 0.7 & -1.7 & 0.12 \\
\hline ALT & 8.1 & 22.1 & 7.4 & 1.1 & 0.30 \\
\hline AST & 6.2 & 17.8 & 5.9 & 1.0 & 0.32 \\
\hline ALP & -1.4 & 18.1 & 6.0 & -0.2 & 0.82 \\
\hline
\end{tabular}

Abbreviations: TB, total bilirubin; ALT, alanine transaminase; AST, aspartate transaminase; ALP, alkaline phosphatase; SD, standard deviation; SE, standard error.

Transcorneal steady-state levels were achieved more rapidly in human corneas (4 hours) than in rabbit corneas (12 hours).

\section{Discussion}

Glaucoma is a progressive optic neuropathy and represents a leading cause of blindness worldwide. ${ }^{18}$ All forms of glaucoma therapy share the common target of lowering intraocular pressure to a level that minimizes or eliminates the risk of damage to the optic nerve. Reduction and control of increased intraocular pressure in most glaucomas is classically achieved by long-term topical therapy as first-line treatment. ${ }^{1}$

Pharmacological and histological studies support a direct role of ocular cannabinoid receptors in the intraocular pressure reduction induced by cannabinoids.
Cannabinoid receptors have been found in the ocular tissues of the human eye, including the ciliary epithelium, the trabecular meshwork, Schlemm's canal, ciliary muscle, ciliary body vessels, and retina. ${ }^{2,19}$ High levels of cannabinoid mRNA have also been demonstrated in the ciliary body. ${ }^{2,20}$ The anatomical distribution of these receptors suggests a possible influence of endogenous cannabinoids on trabecular and uveoscleral outflow as well as on production of aqueous humor. Tetrahydrocannabinol, the main psychoactive component of cannabis, decreases secretion of the ciliary processes and leads to dilatation of the ocular blood vessels, possibly via a beta-adrenergic action., ${ }^{2,21}$ In addition, cannabinoids may inhibit calcium influx through presynaptic channels and in this way reduce noradrenaline release in the ciliary body, leading to a decrease in production of aqueous humor. ${ }^{2,22}$ Furthermore, it has been proposed that cannabinoids may have a vasodilatory effect on the blood vessels of the anterior uvea, thus improving uveoscleral outflow. ${ }^{2,20}$ Some cannabinoids may also influence intraocular pressure via a prostaglandin-mediated mechanism. ${ }^{23,24}$ Recent studies have not only demonstrated the intraocular pressure-lowering capability of cannabinoids, but have also documented its neuroprotective properties, which are an additional advantage when treating patients with glaucoma.

In glaucoma, the final common pathway leading to visual loss is the selective death of retinal ganglion cells as a result of apoptosis. Apoptosis is initiated by axonal injury at the optic disc, either by ischemia and/or compression. ${ }^{2}$ In ischemia, glutamate is released and leads to activation of one of several pathways that eventually lead to apoptosis. There is

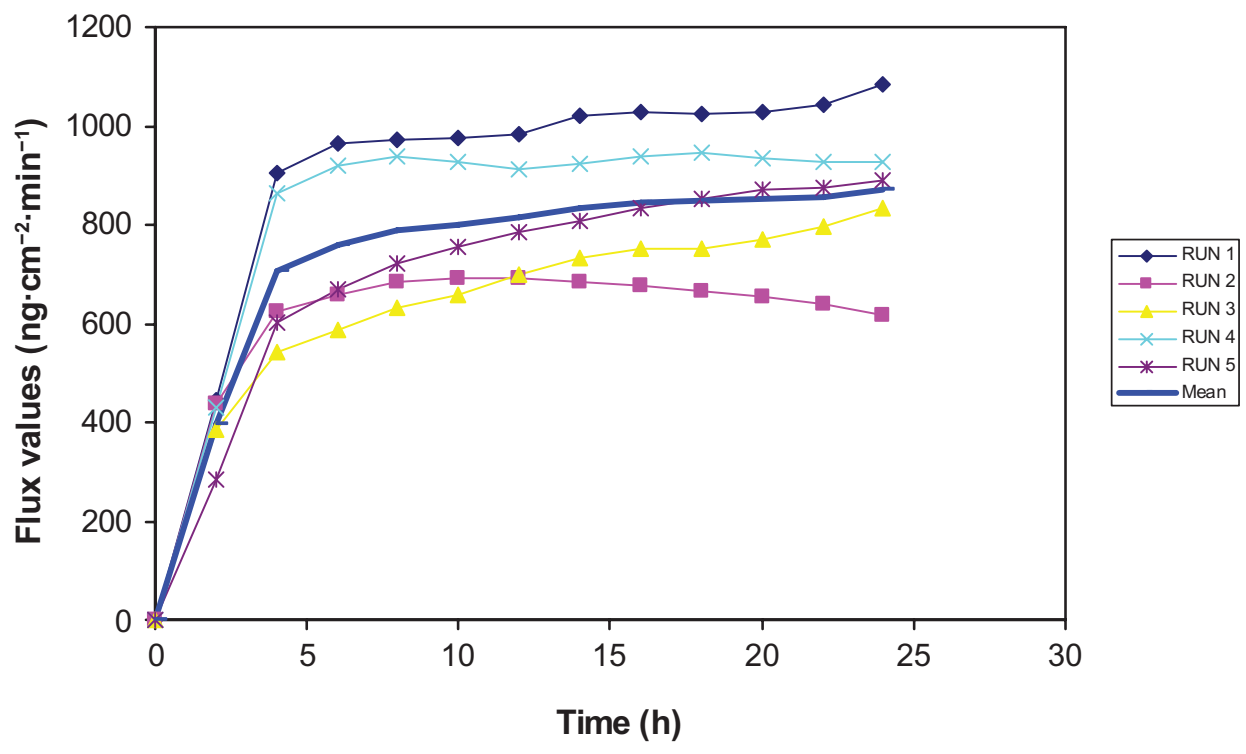

Figure I Diffusion of paracetamol through human cornea. 


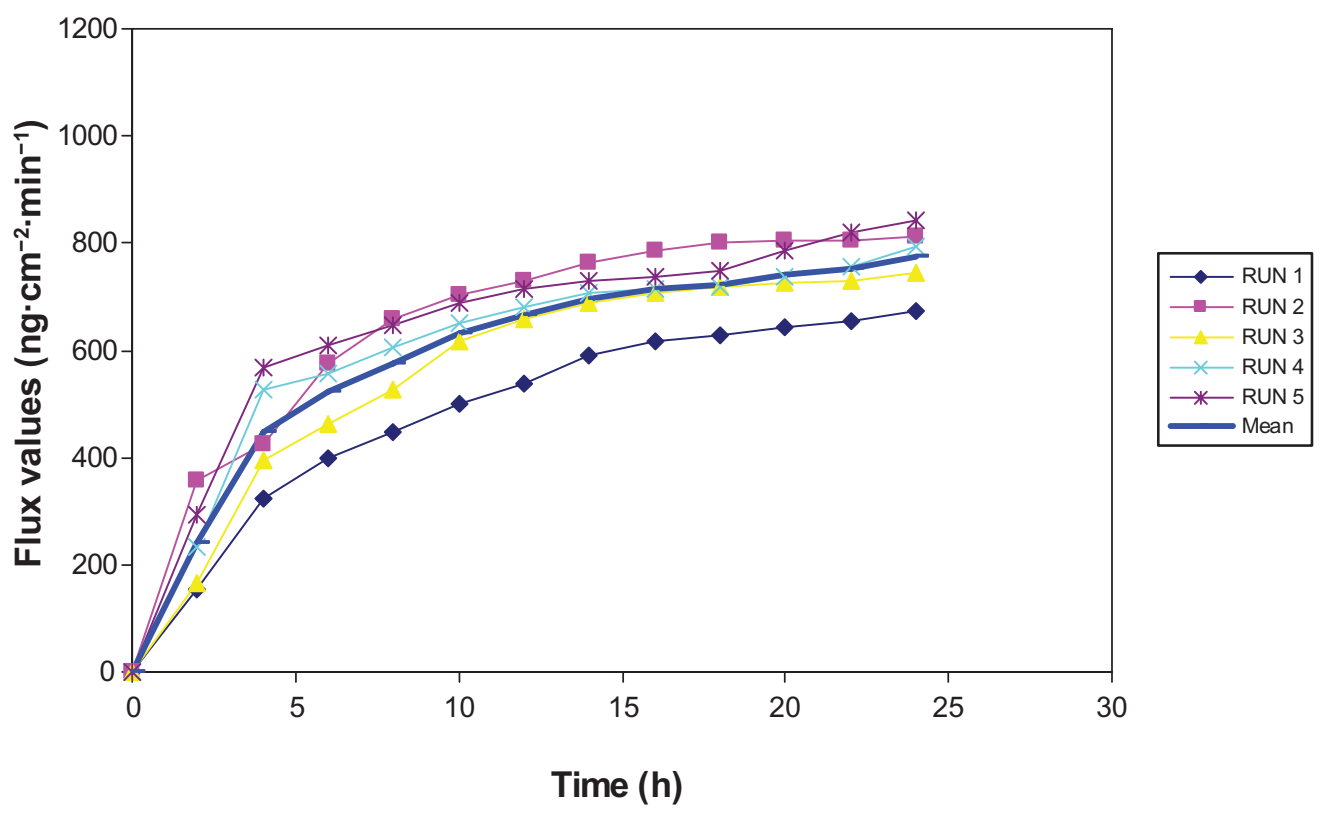

Figure 2 Diffusion of paracetamol through rabbit cornea.

evidence that tetrahydrocannabinol inhibits glutamic acid and thus prevents a cascade of events leading to apoptosis and death of retinal ganglion cells. The potential role of cannabinoids in improving ocular blood flow due to their innate vasorelaxant properties have also been postulated. ${ }^{2}$ The possible role of endothelin-1, a mediator involved in the regulation of local circulation by causing vasoconstriction, has been described previously in the pathogenesis of Raynaud's phenomenon and ischemic heart disease. ${ }^{25}$ A possible link between primary open angle glaucoma and endothelin-1 is now postulated. It has been suggested that patients with this condition may have abnormally increased levels of endothelin-1 in response to vasospastic stimuli. ${ }^{2,26,27}$ It was also demonstrated that endogenous cannabinoids are able to inhibit vasoconstriction via reduction of endothelininduced calcium mobilization. ${ }^{28}$ Thus, cannabinoids may have beneficial properties in arresting ischemia-induced optic nerve damage, which is an added benefit in the treatment of patients with open angle glaucoma. Clearly, there are several potential mechanisms of action in glaucoma if the cannabinoid receptor can be successfully stimulated.

The results of our pilot clinical study demonstrate that both topical levobunolol and oral paracetamol significantly reduced intraocular pressure from the untreated baseline at weeks 1 and 2 in patients with primary open angle and angle recession glaucoma. These patients were included in the study because both these glaucomas are "open angle" glaucomas, and presumably would respond similarly to treatment with either agent. In the levobunolol group, reduction in intraocular pressure increased from $25 \%(7.5 \mathrm{mmHg})$ at week $1 \%$ to $29 \%(9 \mathrm{mmHg})$ at week 2 , while in the oral paracetamol subgroup, reduction in intraocular pressure decreased from $29 \%(8.8 \mathrm{mmHg})$ at week $1 \%$ to $21 \%(6.5 \mathrm{mmHg})$ at week 2 (Figure 3). The change in intraocular pressure from week 1 to 2 in both subgroups was not clinically or statistically significant. The change in reduction of intraocular pressure in the paracetamol group may possibly be due to desensitization of cannabinoid receptors to the cannabinomimetic metabolic products of paracetamol. Equal lowering of intraocular pressure from baseline was obtained in the levobunol and paracetamol groups approximately 1.3 weeks following commencement of the study (Figure 3). The intraocular pressure-lowering effect of paracetamol (21\%) is consistent with previous reports of the ocular hypotensive efficacy of alpha-2 selective adrenergic agonists $(20 \%-25 \%)$, topical carbonic anhydrase inhibitors (20\%-25\%), and pilocarpine (20\%-25\%). ${ }^{29}$

Results of the Early Manifest Glaucoma Treatment Study suggest that each $1 \mathrm{mmHg}$ of additional intraocular pressure-lowering reduces the risk of glaucomatous progression by approximately $10 \%$ in patients with early glaucoma. ${ }^{30}$ Often this may be achieved by adding an additional drug with a different mechanism of action to the treatment regimen. Paracetamol, as a prodrug for the active cannabinoid, AM404, which acts on the cannabinoid receptor, may add such value to the available treatment armementarium. Ocular administration of the metabolite, AM404, decreased intraocular pressure in rabbits, but provoked an initial ocular hypertension response in a study by Laine et al. ${ }^{31}$ 


\section{IOP in the two study groups at each measurement}

( $\mathrm{mmHg})$

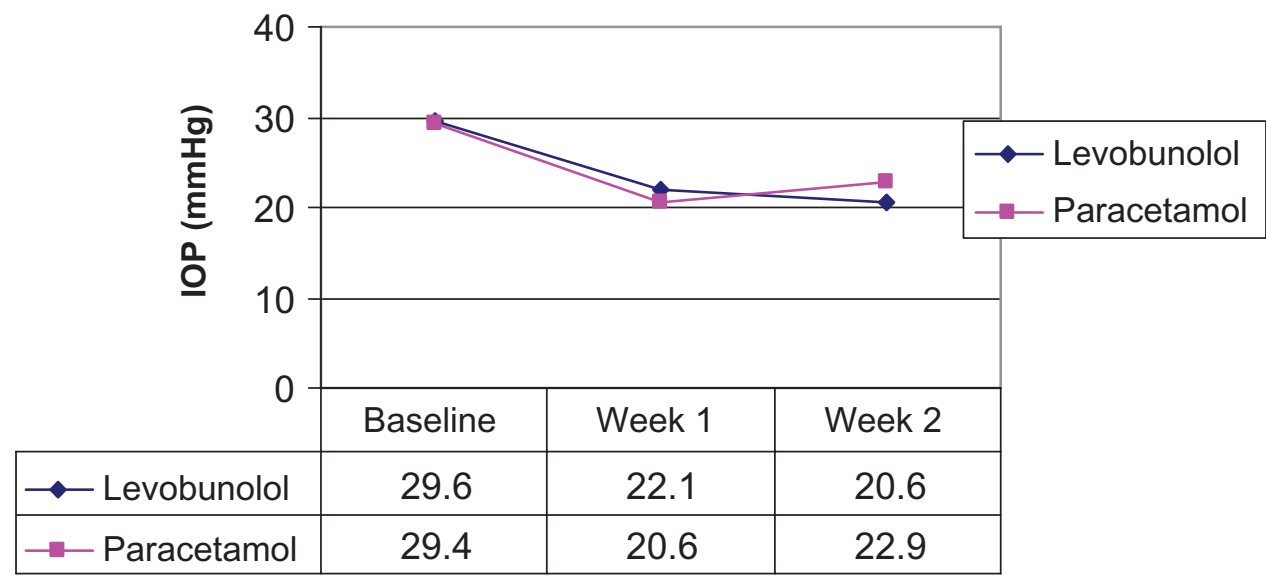

Time

Figure 3 Intraocular pressure (IOP) $(\mathrm{mmHg})$ versus time from baseline in the levobunolol and paracetamol groups.

Paracetamol is considered to be safe in oral doses of up to $4 \mathrm{~g}$ daily in adults. ${ }^{32}$ None of the patients in this study met the standard criteria for drug-induced hepatotoxicity as set out by the DILI Network criteria. ${ }^{11,12}$ However, a recent participantblinded, diet-controlled study in selected healthy volunteers taking $4 \mathrm{~g}$ of paracetamol daily, either alone or in combination with selected opioids or placebo, was conducted..$^{33}$ These researchers reported that $76 \%$ of subjects in the paracetamol group had concentrations of ALT above the upper limit of the reference range, and that $39 \%$ of these subjects had an elevation that was more than three times the upper limit of the reference range, and $25 \%$ had more than five times the upper limit of the reference range. None of those who had received placebo had an increase to these levels. On the other hand, other long-term studies with paracetamol have failed to detect evidence of liver injury. ${ }^{34,35}$ No statistically significant changes in liver function, systolic/diastolic blood pressure, or heart rate were observed over the 2-week period of the present study.

In a recent pilot study of sublingual delta-9-tetrahydrocannabinol and cannabidiol, Tomida et $\mathrm{al}^{36}$ suggested that delta-9-tetrahydrocannabinol lowered intraocular pressure significantly in the short term, but that cannabidiol did not, thereby alluding to the need for further research on the clinical effect of systemically administered cannabinoidlike molecules in glaucoma. Using the same molecule (delta-9-tetrahydrocannabinol) in an experimental rat model, Crandall et al ${ }^{37}$ suggested that the molecule could have neuroprotective effects over and above its intraocular pressurelowering potential. If cannabinoids and their precursors (like paracetamol) do have a neuroprotective effect on ganglion cells, especially if independent of intraocular pressure reduction, they could offer another treatment modality in patients with glaucoma.

Permeation of chemical substances through the human corneal tissue epithelium is dependent not only on the nature, conformation, lipid/water partition coefficient, and degree of ionization of the molecules involved, but also on their size. ${ }^{15}$ The molecular weight of paracetamol is $151.16 \mathrm{~g} / \mathrm{mol}$, so it is a relatively small molecule and our in vitro observations have demonstrated its ability to penetrate the human cornea rapidly and reach high steady-state levels within 4 hours.

\section{Limitations}

One major limitation of this pilot study is the lack of a placebo-controlled arm. Because these were patients with known disease and needing therapy for their raised intraocular pressure, we were ethically bound to treat all of them. The short duration of the study and small sample size was chosen to satisfy patient safety concerns. This small sample size might thus be open to bias, but serves as a pilot study for ongoing clinical studies. The investigator was not masked to the medication, study eye, or when measuring the intraocular pressure, but because a single investigator performed all the measurements, we believe this limited any potential bias possible in our study design. Although diurnal variability of intraocular pressure was not taken into account, every attempt was made to measure the intraocular pressure at $9 \mathrm{am}$. The amount of intraocular pressure reduction achieved by levobunolol $0.5 \%$ was similar to that quoted by the European 
Glaucoma Society for $\beta$-blockers, whereas that achieved by paracetamol was similar to the degree of reduction achieved with topical application of cannabinoids or pilocarpine. ${ }^{29,38,33}$ Further, we relied on patient confirmation and not on serum paracetamol concentration levels to confirm compliance.

\section{Conclusion and future directions}

The results of this study suggest that paracetamol $1 \mathrm{~g}$ taken orally as a 6-hourly dose, reduces intraocular pressure in patients with open angle glaucoma and/or angle recession glaucoma in a manner comparable with that of several other intraocular pressure-lowering agents available today, and over a short period of therapy. Based on the in vitro ability of paracetamol to penetrate human corneal tissue, the next logical step would be to assess its tolerability and efficacy as a topical preparation in a well controlled study.

\section{Acknowledgments}

The authors thank Heiner Seifart and Armorél D van Eyk, Division of Ophthalmology, Faculty of Medicine and Health Sciences, University of Stellenbosch, South Africa, for their assistance with the in vitro experiments, and Justin Harvey for his statistical analysis.

\section{Disclosure}

The senior author (DM) discloses that he is the inventor of a published PCT patent application, number WO2009/019555, which has been filed in the name of the University of Stellenbosch, South Africa. This patent relates in part to the use of topical paracetamol for glaucoma. The principal author (NM) has no conflicts of interest to report in this work.

\section{References}

1. Meyer D, van Schalkwyk J. Textbook of Ophthalmology: A Review of Current Medical Therapy for Primary Open Angle Glaucoma. New Delhi, India: Jaypee Brothers; 2002:3.

2. Tomida I, Pertwee RG, Azuara-Blanco A. Cannabinoids and glaucoma. Br J Ophthalmol. 2004;88:708-713.

3. Thakur GA, Nikas SP, Makriyannis A. CB1 cannabinoid receptor ligands. Mini Rev Med Chem. 2005;5:631-640.

4. Morse HN. Ueber eine neue Darstellungsmethode der Acetylamidophenole. [About a new method of synthesis of Acetylamidophenole]. Ber Deutscher Chem Ges. 1878;11:232-233. German.

5. Hogestatt ED, Jonsson BA, Ermund A, et al. Conversion of acetaminophen to the bioactive N-acylphenol-amine AM404 via fatty acid amide hydrolase-dependent arachidonic acid conjugation in the nervous system. J Biol Chem. 2005;280:31405-31412.

6. Ottani A, Leone S, Sandrini M, Ferrari A, Bertolini A. The analgesic activity of paracetamol is prevented by the blockade of cannabinoid CB1 receptors. Eur J Pharmacol. 2006;531:280-281

7. Bertolini A, Ferrari A, Ottani A, Guerzoni S, Tacchi R, Leone S. Paracetamol: new vistas of an old drug. CNS Drug Rev. 2006;12: 250-275.
8. Pacher P, Batkai S, Kunos G. The endocannabinoid system as an emerging target of pharmacotherapy. Pharmacol Rev. 2006;58:389-462.

9. Romano MR, Lograno MD. Cannabinoid agonists induce relaxation in the bovine ophthalmic artery: evidences for $\mathrm{CB} 1$ receptors, nitric oxide and potassium channels. Br J Pharmacol. 2006;147:917-925.

10. Pinar-Sueiro S, Rodríguez-Puertas R, Vecino E. Cannabinoid applications in glaucoma. Arch Soc Esp Oftalmol. 2011;86:16-23.

11. Ostapowicz G, Fontana RJ, Schiodt FV, et al. Results of a prospective study of acute liver failure at 17 tertiary care centers in the United States. Ann Intern Med. 2002;137:947-954.

12. Heard K, Green JL, Bailey JE, et al. A randomized trial to determine the change in alanine aminotransferase during 10 days of paracetamol (acetaminophen) administration in subjects who consume moderate amounts of alcohol. Aliment Pharmacol Ther. 2007;26:283-290.

13. Van der Bijl P, Van Eyk AD, Meyer D. Effects of three penetration enhancers on transcorneal permeation of cyclosporine. Cornea. 2001;20: 505-508.

14. Van der Bijl P, Engelbrecht AH, Van Eyk AD, Meyer D. Comparative permeability of human and rabbit corneas to cyclosporine and tritiated water. J Ocul Pharmacol Ther. 2002;18:419-427.

15. Van der Bijl P, Van Eyk AD, Seifart HI, Meyer D. Diffusion of metronidazole released from aqueous solution and a gel through human and rabbit corneas. J Ocul Pharmacol Ther. 2004;20:421-429.

16. Van Eyk AD, Van der Bijl P, Meyer D. In vitro diffusion of the immunosuppressant tacrolimus through human and rabbit corneas. $J$ Ocul Pharmacol Ther. 2007;23:146-151.

17. Ostapowicz G, Fontana RJ, Schiodt FV, et al. Results of a prospective study of acute liver failure at 17 tertiary care centers in the United States. Ann Intern Med. 2002;137:947-954.

18. Quigley HA. Number of people with glaucoma worldwide. $B r J$ Ophthalmol. 1996;80:389-393.

19. Straiker A, Maguire C, Makie K, et al. Localization of cannabinoid $\mathrm{CB} 1$ receptors in the human anterior eye and retina. Invest Ophthalmol Visual Sci. 1999;40:2442-2448.

20. Porcella A, Casellas P, Gessa GL, et al. Cannabinoid receptor CB1 mRNA is highly expressed in the rat ciliary body: implications for the antiglaucoma properties of marihuana. Mol Brain Res. 1998;58:240-245.

21. Green K, Pederson JE. Effect of D9-tetrahydrocannabinol on aqueous dynamics and ciliary body permeability in the rabbit. Exp Eye Res. 1973;15:499-507.

22. Sugrue MF. New approaches to antiglaucoma therapy. J Med Chem. 1997;40:2793-2809.

23. Green K, Podos SM. Antagonism of arachidonic acid-induced ocular effects by D9-tetrahydrocannabinol. Invest Ophthalmol Vis Sci. 1974;13:422-429.

24. Green K, Krease EC, McIntyre OL. Interaction between D9-tetrahydrocannabinol and indomethacin. Ophthalmic Res. 2001;33:217-220.

25. Gray GA, Battistini B, Webb DJ. Endothelins are potent vasoconstrictors, and much more besides. Trends Pharmacol Sci. 2000;21:38-40.

26. Haeffliger IO, Meyer P, Flammer J, et al. The vascular endothelium as a regulator of the ocular circulation: a new concept in ophthalmology? Surv Ophthalmol. 1994;39:123-132.

27. Nicolela MT, Ferrier SN, Morrison CA, et al. Effects of cold-induced vasospasm in glaucoma. The role of endothelin-1. Invest Ophthalmol Vis Sci. 2003;44:2565-2572.

28. Mechoulam R, Panikashivili D, Shohami E. Cannabinoids and brain injury: therapeutic implications. Trends Mol Med. 2002;8:58-61.

29. European Glaucoma Society. Terminology and Guidelines for Glaucoma, 2nd ed. Savona, Italy: Dogma; 2003.

30. Heijl A, Leske MC, Bengtsson B, et al; Early Manifest Glaucoma Trial Group. Reduction of intraocular pressure and glaucoma progression: results from the Early Manifest Glaucoma Trial. Arch Ophthalmol. 2002;120:1268-1279.

31. Laine K, Jarvinen T, Savinainen J, Laitinen JT, Pate DW, Jarvinen K. Effects of topical nandamide-transport inhibitors, AM404 and olvanil, on intraocular pressure in normotensive rabbits. Pharm Res. 2001;18: 494-499. 
32. Moynihan R. FDA fails to reduce accessibility of paracetamol despite 450 deaths a year. BMJ. 2002;325:678.

33. Watkins PB, Kaplowitz N, Slattery JT, et al. Aminotransferase elevations in healthy adults receiving 4 grams of paracetamol daily: a randomized controlled trial. JAMA. 2006;296:87-93.

34. Temple AR, Benson GD, Zinsenheim JR, Schweinle JE. Multicenter, randomized, double-blind, active-controlled, parallel-group trial of the long-term (6-12 months) safety of paracetamol in adult patients with osteoarthritis. Clin Ther. 2006;28:222-235.

35. Bradley JD, Brandt KD, Katz BP, Kalasinski LA, Ryan SI. Comparison of an antiinflammatory dose of ibuprofen, an analgesic dose of ibuprofen, and paracetamol in the treatment of patients with osteoarthritis of the knee. N Engl J Med. 1991;325:87-91.
36. Tomida I, Azuara-Blanco A, House H, Flint M, Pertwee RG, Robson PJ. Effect of sublingual application of cannabinoids on intraocular pressure: a pilot study. J Glaucoma. 2006;15:349-353.

37. Crandall J, Matragoon S, Khalifa YM, et al. Neuroprotective and intraocular pressure lowering effects of (-) $\Delta 9$-tetrahydrocannabinol in a rat model of glaucoma. Ophthalmic Res. 2007;39:69-75.

38. Martin BR. Cellular effects of cannabinoid. Pharmacol Rev. 1986;38: $45-74$.
Clinical Ophthalmology

\section{Publish your work in this journal}

Clinical Ophthalmology is an international, peer-reviewed journal covering all subspecialties within ophthalmology. Key topics include: Optometry; Visual science; Pharmacology and drug therapy in eye diseases; Basic Sciences; Primary and Secondary eye care; Patien Safety and Quality of Care Improvements. This journal is indexed on

Submit your manuscript here: http://www.dovepress.com/clinical-ophthalmology-journal

\section{Dovepress}

PubMed Central and CAS, and is the official journal of The Society of Clinical Ophthalmology (SCO). The manuscript management system is completely online and includes a very quick and fair peer-review system, which is all easy to use. Visit http://www.dovepress.com/ testimonials.php to read real quotes from published authors. 